
\title{
$\begin{array}{ll}\text { Research Square } & \begin{array}{l}\text { Preprints are preliminary reports that have not undergone peer review. } \\ \text { They should not be considered conclusive, used to inform clinical practice, } \\ \text { or referenced by the media as validated information. }\end{array}\end{array}$ \\ Isolation, Molecular Identification of Mycoplasma Putrefaciens Local Strains and Its Associated Pathological Lesions in Goats
}

\section{Muhammad Saeed}

The University of Agriculture Peshawar

Farhan Anwar ( $\square$ farhan82@aup.edu.pk)

The University of Agriculture Peshawar https://orcid.org/0000-0001-6024-1269

\section{Farhan Anwar Khan}

The University of Agriculture Peshawar

\section{Faiz Ur Rehman}

The University of Agriculture Peshawar

\section{Hayatullah Khan}

The University of Agriculture Peshawar

\section{Faisal Ahmed}

The University of Agriculture Peshawar

\section{Mehboob Ali}

The University of Agriculture Peshawar

\section{Mushtaq Ahmed}

The University of Agriculture Peshawar

\section{Qudrat Ullah}

The University of Agriculture Peshawar

\section{Aamir Khan}

The University of Agriculture Peshawar

\section{Research Article}

Keywords: Goats, Mycoplasma putrifaciens, Isolation, PCR, Histopathology

Posted Date: December 6th, 2021

DOI: https://doi.org/10.21203/rs.3.rs-1043281/v1

License: (c) (1) This work is licensed under a Creative Commons Attribution 4.0 International License.

Read Full License 


\section{Abstract}

Mycoplasma putrifaciens (Mp) is a dreadful pathogen that causes a severe, usually fatal disease in domestic goats known as MAKePS syndrome in small ruminants. The present lack of effective diagnostic and control measures leaves Pakistani farmers at perpetual great risk of financially disastrous MAKePS outbreaks. Thus far, very limited information is available on the detection and molecular characterization of the unique $M p$ strains prevalent in Pakistan. This study was proposed to apply modern molecular techniques to characterize endemic $M p$ isolates and their associated specific lesions in goats to devise an effective control strategies. For the collection of samples Northern areas of Pakistan were focused including Chitral, Gilgit and Swat. Samples were collected from Mycoplasma putrifaciens suspected animals (Chitral $n=200$, Gilgit $n=200$, Swat $n=200$ ). Clinical samples including nasal swab (NS) and synovial fluid (SF) from live animals $(n=50)$, whereas pleural fluid (PF) and lungs samples from dead goats $(n=50)$ were collected from each representative northern area of Pakistan. All samples were subjected to isolation of $\mathrm{Mp}$ local strain, while tissue samples were examined for pathological lesions. Culture positive PPLO broth was first confirmed for Mp by specific PCR. From Gilgit Baltistan $38.83 \%$ samples were found positive for $M p$ by PCR, whereas $25 \%$ and $19.38 \%$ samples from Chitral and Swat, respectively, were detected positive for $M p$ by generating an amplicon of $540 \mathrm{bp}$. The PCR positive PPLO broth samples were cultured on PPLO agar for isolation of $M p$. A single colony with fried egg like appearance was picked and sub-cultured in PPLO broth for purification and later on confirmed with PCR. The Histopathological study of lungs showed that there was emphysema, rupture of alveoli, in bronchioles ciliated epithelium were sloughed and infiltration of leukocytes. We successfully isolated and purified Mp local strain prevalent in northern area of Pakistan. The Mp was detected prevalent in 27.76\% goats of Northern regions by PCR. This study laid down a foundation to develop an effective diagnostic kit and vaccine against $M p$ infection in Goats.

\section{Introduction}

In Pakistan, livestock is a major subsector of agriculture that contributes $60.54 \%$ to the agriculture gross domestic product (GDP) (Economic survey, 2018-2019). Pakistan have the largest population of goats among livestock. Goat is considered as poor man's cow in Indo-Pak sub-continent (Rahman et al., 2003). The population of goat is facing diversified problems in the country because of poor management practices, low feeding and infectious and non-infectious diseases. Among the infectious diseases, Mycoplasmosis causes great loss to animals because of high morbidity and mortality (Siddique et al., 2012). The Mycoplasma belongs to class Mollicutes having no cell wall, prokaryotes, small size and have unusually small genomes approximately 0.58 to $2.20 \mathrm{Mb}$. (Khan et al., 2016;2018). . In small ruminants it cause respiratory disease, arthritis, eye lesions, genital lesions and mastitis (Nicholas, 2002; Sharif and Muhammad, 2009).

Mycoplasma putrefaciens is responsible for great economic loses in developing countries in term of decrease milk production, meat, hide and hair in most countries (OIE, 2000). Mycoplasma putrefaciens adversely affect the goat population throughout the world causing morbidity and an acute illness with 
mortality. Mycoplasma putrefaciens is considered as an etiological agent of the contagious agalactiae syndrome in goats by the world organization (OIE) for animal health (Manual, Paris, France 2000) characterized by Mastitis, Arthritis, Keratoconjunctivitis, Pneumonia, and Septicemia (MAKePS) (Thiaucourt et al., 1996). Mycoplasma putrefaciens also found in ear canal as a commensal organisms (Cottew GS et al., 1981). Mycoplasma putrifaciens is closely related to mycoplasma mycoides cluster that consist of 5 major members, highly pathogenic to ruminants including M. mycoides subsp. capri, $M$. mycoides subsp . mycoides, M. capricolum subsp. capricolum, M. capricolum subsp. capripneumoniae, and M. leachii (Manso-Silván L et al., 2007) but different from these mycoplasmas because the first sign which appear in Mp infection is mastitis (Adler et al., 1980).The most impressive biochemical characteristic that differentiate Mycoplasma putrifaciens from all other mycoplasmas is the production of bed smell that occur in cultured broth (Tully et al 1974). The gross pathology macroscopic study revealed arthritis (increase in the size of the carpel joints) and respiratory signs such as serous to mucoid nasal discharge and temperature range from 38.1 to $40 C^{\circ}$ (Rodriguez et al., 1995).

Looking at the economic losses, high morbidity and mortality of small ruminants due to Mycoplasma putrifaciens a rapid, specific and sensitive detection test was developed called Polymerase chain reaction in order to isolate, identify and characterize the Mycoplasma putrifaciens that has never been reported in northern regions of Pakistan. This study will be helpful for the researcher to eradicate this fatal disease.

The Histopathological study $M p$ showed intestinal lesions characterized by a multi focal necrotichemorrhagic enteritis and areas of catarrhal enteritis with fusion of villi and infiltration of cells which are composed of mainly neutrophils and eosinophil's. The joints showed acute fibrinopurulent arthritis with hyperplasia of the synovial epithelium (DaMassa and others 1984, 1987, 1992).

\section{Materials And Methods}

\section{Study Area}

The study was approved by the ethical committee of College of Veterinary Sciences, Faculty of Animal Husbandry and Veterinary Sciences, The University of Agriculture, Peshawar. A total of 600 samples were collected from Northern region (Chitral, Gilgit Baltistan, Swat) of kpk, Pakistan during November 2017 to December 2018. All the samples were collected from naturally infected small ruminants having respiratory signs like coughing, muco-purulent nasal discharge, along with decrease milk production in lactating animals.

\section{Sample size and Sampling}

The samples for the bacterial isolation were collected that comprised of nasal cavity through nasal swab, synovial fluid from live animals by aspiration, pleural fluid and lungs tissue were taken from dead animals suspected for Mycoplasma putrifaciens. Total 600 samples were collected, 200 from each region. Sterile cotton swab were used for collection of nasal discharge which are inserted gently and touch nasal passage of the goat to get the secretion. Pleural fluid was collected with the help of sterile 
$5 \mathrm{ml}$ syringe and pour into screw caped sterile $15 \mathrm{ml}$ falcon tube and placed in icebox immediately. Lung sample were collected aseptically between both normal and morbid part (consolidation, red hepatization) of lung. Lung tissues were also preserved in $10 \%$ neutral buffered formalin for Histopathological examination. All the samples were immediately preserved in icebox at $-4 \mathrm{C}^{\circ}$ and transported to Pathology laboratory, College of Veterinary Sciences, Faculty of Animal Husbandry and Veterinary Sciences, The University of Agriculture, Peshawar for further processing.

\section{Cultivation of Samples}

Nasal swab, Synovial fluid and Pleural fluid were cultured in PPLO broth media with the composition of PPLO broth (Sigma, USA) 2.1\% supplemented with 0.5\% Sodium pyruvate (Sigma, USA), $0.09 \%$ Yeast extract (Sigma, USA), 0.2\% glucose (Sigma, USA), 20\% Horse Serum (New Zealand). Lung tissues were first minced and then cultured in PPLO broth media. All the tubes were placed at $37 \mathrm{C}^{\circ}$ in $5 \% \mathrm{CO}_{2}$ incubator (New Brunswick, Galaxy48S, UK) for 3-4 days. The samples were checked every 12 hours for color change, whirling movement and turbidity. One tube containing Sterile PPLO broth having no sample were also kept as a negative control.

Isolation and Purification of Mycoplasma putrifaciens

Mycoplasma putrifaciens positive cultured samples were processed further for isolation and purification. Primary positive culture was passed through PVDF syringe filter having pore size $0.45 \mu \mathrm{m}$ for removing large debris and other field bacteria. After filtration positive samples were cultured and sub-cultured in PPLO broth and Agar, incubated for 3-4 days. This process was repeated 4-5 times to get a single pure colony of Mycoplasma putrifaciens. The plates were then examined under CCD microscope (Olympus, Japan) at $4 X$, and $10 X$ on daily basis for 3-4 days.

\section{DNA Extraction}

The culture showing turbidity, whirling movement were transferred to $1.5 \mathrm{ml}$ eppendorf tube and centrifuged at 10000rpm for 15 minutes. Supernatant was discarded and genomic DNA was extracted through DNA extraction kit (Thermoscientific, USA). Concentration and purity was checked through Nanodrop (Multiskan, Thermoscientific, USA) which was in the range of $30-50 \mathrm{ng} / \mu \mathrm{l}$.

\section{Polymerase Chain Reaction}

Polymerase chain reaction (PCR) tests for the detection of Mycoplasma Putrifaciens was performed on purified DNA samples by using specie specific primers Mp primers: Forward: (5'-

GCGGCATGCCTAATACATGC-3/) Reverse: (5/ AGCTGCGGCGCTGAGTTCA-3/) with the amplicon size is $540 \mathrm{bp}$ (Shankster et al, 2002). The primer used in this study were synthesized by Invitrogen (USA). About $1.5 \mu \mathrm{l}$ sample of each purified genomic DNA was amplified in 25 $\mu \mathrm{l}$ of PCR with a composition of $10 \mu \mathrm{l}$ master mix " $1.5 \mathrm{mM} \mathrm{Mgcl} 2,200 \mu \mathrm{M}$ of each dNTP. 1 unit Taq polymerase and $10 \mu \mathrm{M}$ of each forward and reverse primers". All the PCR tubes were subjected to Gradient Thermal cycler machine (Bio-Rad,USA) with a initial denaturation at $95^{\circ} \mathrm{C}$ for 3 minutes followed by $34 \mathrm{X}$ (cycles) consisting of 60 seconds of 
denaturation at $94^{\circ} \mathrm{C}, 60$ seconds of annealing at $59.5^{\circ} \mathrm{C}$. Extension for 60 seconds at $72^{\circ} \mathrm{C}$ and Final extension for 5 minutes at $72^{\circ} \mathrm{C}$. Gel red (Thermo, USA) was added $1 \%$ agrose gel for visualization the PCR products by using ultraviolet gel documentation system (Fasgene, Germany).

\section{Results}

Clinical signs and lesions observed in Mycoplasma putrifaciens in suspected goats

Clinically suspected goats for Mycoplasma putrifaciens shows Hyperthermia, coughing, mucopurulent nasal discharge, conjunctivitis, arthritis and mastitis were the prominent signs that recorded during this study. The postmortem examination shows unilateral hepatization, consolidation and straw color fluid present in lungs (Fig. 1)

\section{Cultivation of field samples}

Out of total 600 samples 317 samples were positive upon cultivation showing whirling movement by shaking, turbidity and color change (Fig. 2). Separately, of nasal samples (52.66\%), synovial fluid (42.66\%), pleural fluid $(59.33 \%)$ and lung tissues $(56.66 \%)$ showed growth movement for mycoplasma putrifaciens when incubated for 2-3 days in 5\% CO2 incubator. Each of the positive culture broth from nasal swab, synovial fluid, pleural fluid and lung tissues gives a circle like colonies having a very small dot in the center of the colony post incubation when cultured on PPLO agar media (Fig. 4).

\section{Molecular characterization of Mycoplasma putrifaciens by PCR}

DNA was extracted from all cultured positive samples and subjected to PCR by targeting 16S rRNA gene of mycoplasma putrifaciens. PCR results revealed mycoplasma putrifaciens isolates in 88 samples by generating an amplicon of $540 \mathrm{bp}$ (Fig. 3). The positive samples for mycoplasma putrifaciens through PCR includes 21(26.58\%), 5(7.81\%), 27(30.33\%), 35(41.17\%) samples from nasal swab, synovial fluid, pleural fluid and lung tissues.

\section{Discussion}

This works describes the isolation and identification of Mycoplasma putrifaciens for the first time in southern regions of Pakistan from goats having respiratory signs along with mastitis, arthritis, keratocunjunctivitis, septicemia, and pneumonia ((MAkePS). $M p$ is also the causative agent of contagious agalactia syndrome (OIE, 2008). M. agalactiae, M. putrefaciens which are not members of Mycoplasma mycoids cluster mostly cause complications when occur along with cluster. (Sadique et al., 2012,). The isolation and identification of $M p$ is very difficult work because of slow growing rate and require a special media for culturing.

In present study the molecular prevalence of $M p$ was undertaken by using the PCR assay for the first time in southern regions of kpk, Pakistan. Undoubtedly, the previous study on Mycoplasma confirm that it is 
widely spread in Pakistan. For identification of Mycoplasma there are many techniques such as conventional and non-conventional but most of the time gives false negative result. For proper confirmation of Mycoplasma it is important to culture the suspected samples but in most cases it is failed because of lack of diagnosis of infected animals and second one is the media which are used for culturing the Mycoplasma is expensive and takes time to grow.

Mp was isolated successfully when cultured on modified PPLO media from different samples comprised of nasal swab, synovial fluid, Pleural fluids and lungs tissue. The most appropriate sample for the isolation of Mycoplasma is pleural fluid. Same findings were also observed by (Sadique et al., 2012, Thiacourt et al., 1994). Such investigations are confirmed by the fact that Mycoplasma cell membrane have lipoglycan that triggers the acute inflammation leads to severe exudation. The Mycoplasma livability increases as it is deeply present in host tissue.

The presence of disease in different selected areas confirms that Gilgit Baltistan have high prevalence of $M p$ by comparing to swat and chitral. This above statement is proved by the physical features and location of Gilgit Baltistan that are mostly hilly areas and harsh climatic change due to rain on daily basis. The local people of Gilgit Baltistan migrated from their areas because of small ruminants looking for pasture. Due to migration of the local peoples the small ruminants comes in stress that leads to predisposed of the animals to $\mathrm{Mp}$. Due to lack of awareness, education about proper vaccination, diagnosis and treatment $M p$ is spreading from neighbour's countries due to freely movement of nomads from one place to another. The same observations also reported by (Mondal et al., 2004).

For isolation of $M p$ a special media was used called PPLO (Pleuropneumonia like organism).

Mycoplasma is completely dependent on host because to get fatty, amino and nucleic acids, precures of lipid and vitamins. The medium must contain cholesterol which may replace by other sterols like cholesterol or orgosteroll (Rodwell., 1979). Antifungal (Fluconazole) was also added to the medium because of chances of fungal growth in medium is a common problem. Typical fried egg colonies were appeared when streaked on PPLO agar.

Thermo scientific gene jet genomic DNA kit was used for the extraction of DNA from cultured broth showing color change, turbidity and whirling and then perform PCR to confirm the presence of $M p$. By DNA extraction or culturing the Mp positive broth on PPLO agar there was a putrid smell of culture. The findings were also noticed by (Tully et al 1974). PCR is the most sensitive method as compared to biochemical tests as most of the time biochemical tests gives false negative results.

Typical fried egg like colonies were appeared from PCR positive culture broth when streaked on PPLO agar. Same findings were also observed by (shah et al., 2017). The colonies were appeared after 2 to 3 days post culturing. Every single colony was picked up with sterile needle of syringe and pour in PPLO broth in order to obtain pure culture broth and then place in Incubator having $5 \% \mathrm{CO} 2$ at $37 \mathrm{C}^{\circ}$. Out of 200 samples, the total prevalence of MP in Gilgit Baltistan through PCR was 38.85\%; in which the percentage of nasal swab, synovial fluid, pleural fluid and lung tissues were 9, 2, 13 and 16 respectively. In Chitral, $25 \%$ samples were positive having nasal swab $5 \%$, synovial fluid $2 \%$, pleural fluid $9 \%$ and lung tissues 
$13 \%$. The total positive samples in Swat were $19.38 \%$, comprised of $7 \%$ positive samples of nasal swab, $1 \%$ synovial fluid, $5 \%$ pleural fluid and $6 \%$ lung tissues. Same primers were used as used by (Shankster et al., 2002) having amplicon size of $540 \mathrm{bp}$.

Gross pathology during postmortem examination there was polyarthritis, various degree of pneumonia, red hepatization of one lung, pleural fluid was seen that was also reported by (Rodriguez et al., 1994, Peyraud et al., 2003, Awan et al., 2009). The Histopathological study showed arthritis having acute fibrinopurulent hyperplasia of the synovial epithelium. There is congestion in lungs of septal vessels and also alveolar edema along with cell debris and alveolar macrophages.

The $M p$ is highly prevalent throughout Pakistan and cause high economic loss to goat population in northern and southern regions of the country (Fauzia et al., 2016; Shahzad et al., 2012; Saddique et al., 2012).

\section{Declarations}

\section{Acknowledgment:}

The research work was financially supported by the joint research project of The University of Agriculture, Peshawar and Sandia National Laboratories, New Mexico, USA under the Pak-US Science and Technology Cooperation Program, Phase 7, 2017. This program is supported and implemented by the National Academy of Sciences (NAS) in the U.S. and by the Higher Education Commission (HEC) in Pakistan. We are thankful to the Livestock \& Dairy Development (Extension) (L\&DD KPK), and Veterinary Research Institute, Peshawar for their help and support in sampling. We are grateful to Dr. Francois Thiaucourt, and Dr. Lucia Manso-Silvan, CIRAD-INRA ASTRE "Animal, Santé, Territoires, Risques, Ecosystèmes" TA A-117 Campus de Baillarguet 34398, Montpellier Cedex 5, France, for their guidance and technical support.

\section{Statement of Animal Rights:}

This study was approved by the ethical committee of The University of Agriculture Peshawar. All experimental procedures was performed under the institutional guidelines and animal ethics.

\section{Conflict of interest:}

The authors have no conflict of interest to disclose.

4. Author's contribution: MS, FAK, and FR designed and conceived the study. MS, HK, FA, FR, MA, AK and QU carried out the research. MS, FAK, HK, FA, and FR analyzed the data. MS, FAK, HK, and FA wrote the manuscript. FAK, and HR critically reviewed and revised the manuscript.

5. Consent for publication: All the authors showed agreement on the publication of this manuscript in this esteemed journal. 
6. Data Availability: Data sharing not applicable to this article.

\section{References}

Abdela, N., \& Jilo, K., 2016. Impact of climate change on livestock health: A review. Global Veterinaria, 16(5), 419-424.

Arjoon, A. V., Saylor, C. V., \& May, M., 2012. In Vitro efficacy of antimicrobial extracts against the atypical ruminant pathogen Mycoplasma mycoides subsp. capri. BMC complementary and alternative medicine, 12(1), 1-6.

Awan, M. A., Abbas, F., Yasinzai, M., Nicholas, R. A. J., Babar, S., Ayling, R. D. \& Ahmed, Z. 2009.

Prevalence of Mycoplasma capricolum subspecies capricolum and Mycoplasma putrefaciens in goats in pishin district of balochistan. Pakistan Veterinary Journal, 29(4).

Adler, H. E., DaMassa, A. J., \& Brooks, D. L. 1980. Caprine mycoplasmosis: Mycoplasma putrefaciens, a new cause of mastitis in goats. American journal of veterinary research, 41(10), 1677-1679.

Cottew, G. S, \& Yeats, F. R 1981. Occurrence of mycoplasmas in clinically normal goats. Australian veterinary journal, $571,52-53$.

Economic Survey of Pakistan. 2018-2019. Finance Division, Economic Advisors Wing, Ministry of Finance, Govt. of Pakistan, Islamabad.

Economic Survey of Pakistan. 2016-2017. Finance Division, Economic Advisors Wing, Ministry of Finance, Govt. of Pakistan, Islamabad.

DaMassa, A. J., Brooks, D. L., \& Holmberg, C. A. 1984. Pathogenicity of Mycoplasma capricolum and Mycoplasma putrefaciens. Israel journal of medical sciences, 20(10), 975-978.

Fauzia, B., Ferhat, A., Awan, M. A., Aayesha, R., Khan, I. A., Zafar, A. \& Baig, R. M. 2016. Molecular survey on the prevalence of Caprine mycoplasma in the goats of Quetta City of Pakistan. International Journal of Veterinary Science, 5(3), 158-163.

Jilo, K., Abdela, N., \& Adem, A. 2016. Insufficient veterinary service as a major constrants in pastoral area of ethiopia: a review. Journal of Biology, Agriculture and Healthcare, 6(9), 94-101.

Manso-Silván, L., Perrier, X., \& Thiaucourt, F. 2007. Phylogeny of the Mycoplasma mycoides cluster based on analysis of five conserved protein-coding sequences and possible implications for the taxonomy of the group. International Journal of Systematic and Evolutionary Microbiology, 57(10), 2247-2258.

Mondal, D., Pramanik, A. K., \& Basak, D. K. 2004. Clinico-haematology and pathology of caprine mycoplasmal pneumonia in rain fed tropics of West Bengal. Small Ruminant Research, 51(3), 285-295. 
Nicholas, R. A. J. 2002. Improvements in the diagnosis and control of diseases of small ruminants caused by mycoplasmas. Small Ruminant Research, 45(2), 145-149.

OIE, Contagious caprine Pleuropneumonia. 2008. In: Manual of Standards for Diagnostic Tests and Vaccines, Office International des Epizooties, Paris, France, 1000-1012.

OIE, Contagious caprine pleuropneumonia. 2000. Terrestrial Manual. Chapter 2.7.6. Office International Des Epizootics, Paris, France, 04:719.

Peyraud, A., Woubit, S., Poveda, J. B., De la Fe, C., Mercier, P., \& Thiaucourt, F. 2003. A specific PCR for the detection of Mycoplasma putrefaciens, one of the agents of the contagious agalactia syndrome of goats. Molecular and cellular probes, 17(6), 289-294.

Rosegrant, M. W., Ringler, C., Zhu, T., Tokgoz, S., \& Bhandary, P. 2013. Water and food in the bioeconomy: Challenges and opportunities for development. Agricultural Economics, 44(s1), 139-150.

Rahman, S. U., Siddique, M., Hussain, I., Muhammad, K., \& Rasool, M. H. 2003. Standardization of indirect haemagglutination test for monitoring Mycoplasma mycoides subspecies capri antibodies raised in rabbits and goats. Int J Agri Biol, 5, 295-7.

Rodriguez, J. L., Poveda, J. B., Oros, J., Herraez, P., Sierra, M. A., \& Fernandez, A. 1995. High mortality in goats associated with the isolation of a strain of Mycoplasma mycoides subsp. mycoides (large colony type). Journal of Veterinary Medicine, Series B, 42(1-10), 587-593.

Rodriguez, J. L., Poveda, J. B., Gutierrez, C., Acosta, B., \& Fernandez, A. 1994. Polyarthritis in kids associated with Mycoplasma putrefaciens. The Veterinary Record, 135(17), 406-407.

Rodwell, A. W., Rodwell, E. S., \& Archer, D. B. 1979. Mycoplasmas lack a protein which closely resembles aactin. FEMS Microbiology Letters, 5(4), 235-238.

Shah, M. K., Saddique, U., Ahmad, S., Iqbal, A., Ali, A., Shahzad, W., \& Israr, M. 2017. Molecular characterization of local isolates of Mycoplasma capricolum Sub Specie Capripneumoniae in goats (Capra hircus) of Khyber Pakhtunkhwa, Pakistan. Pak Vet J, 37(1), 90-94.

Sadique, U., Chaudhry, Z. I., Younus, M., Anjum, A. A., Idrees, M., Qureshi, M. S., \& Subtain, S. M. 2012. Clinico-pathological study of contagious caprine pleuropneumonia (CCPP) in small ruminants. J Anim Plant Sci, 22(2), 45-50.

Shahzad, W., Munir, R., Khan, M. S., Shakil, M., lqbal, M., \& Rashid, A. 2012. Characterization, molecular diagnosis and prevalence of caprine mycoplasmosis in different areas of Pakistan. Pakistan Journal of Zoology, 44(2).

Sharif, A. and G. Muhammad, 2009. Mastitis control in dairy animals. Pakistan Vet. J. 2009; 29(3):145148. 
Shansster, S., Ayling, R. D., Lenfart, D. D., Mercier, P., \& Nicholas, R. A. J. 2002. 74. Development and evaluation of a PCR to detect Mycoplasma putrefaciens directly from goats. Research in Veterinary Science, (72), 26.

Tambi, N. E., Maina, W. O., \& Ndi, C. 2006. An estimation of the economic impact of contagious bovine pleuropneumonia in Africa. Revue scientifique et technique (International Office of Epizootics), 25(3), 9991011.

Thiaucourt, F., \& Bolske, G. 1996. Contagious caprine pleuropneumonia and other pulmonary mycoplasmoses of sheep and goats. Revue Scientifique et Technique-Office International des Epizooties, 15(4), 1397-1414.

Thiaucourt, F., Bölske, G., Libeau, G., Le Goff, C., \& Lefèvre, P. C. 1994. The use of monoclonal antibodies in the diagnosis of contagious caprine pleuropneumonia (CCPP). Veterinary microbiology, 41(3), 191-203.

Tully, J. G., Barile, M. F., Edward, D. F., Theodore, T. S., \& Ernø, H. 1974. Characterization of some caprine mycoplasmas, with proposals for new species, Mycoplasma capricolum and Mycoplasma putrefaciens. Microbiology, 85(1), 102-120.

Weisburg, W. G., Tully, J. G., Rose, D. L., Petzel, J. P., Oyaizu, H., Yang, D., \& Van Etten, J. 1989. A phylogenetic analysis of the mycoplasmas: basis for their classification. Journal of bacteriology, 171(12), 6455-6467.

\section{Tables}

Table 1 Showing different positive samples for cultivation collected from goats.

\begin{tabular}{|lccc|}
\hline $\begin{array}{l}\text { Types of } \\
\text { sample }\end{array}$ & No of samples & $\begin{array}{l}\text { Mycoplasma +ve samples by } \\
\text { cultivation }\end{array}$ & $\begin{array}{c}\text { Percentage } \\
(\%)\end{array}$ \\
\hline Nasal swab & 150 & 79 & 52.66 \\
\hline Synovial fluid & 150 & 64 & 42.66 \\
\hline Pleural fluid & 150 & 89 & 59.33 \\
\hline Lung tissue & 150 & 85 & 56.66 \\
\hline Total & 600 & 317 & 52.83 \\
\hline
\end{tabular}

Table $2 \mathrm{M} p$ detected through PCR and isolated from goats samples which were positive by cultivation. 


\begin{tabular}{|lllllll|}
\hline Area & $\begin{array}{l}\text { Nasal swab } \\
\text { +ve for } \\
\text { Mp/No of } \\
\text { samples }\end{array}$ & $\begin{array}{l}\text { Synovial fluid } \\
\text { +ve for } \\
\text { Mp/No of } \\
\text { samples }\end{array}$ & $\begin{array}{l}\text { Pleural fluid } \\
\text { +ve for } \\
\text { Mp/No of } \\
\text { samples }\end{array}$ & $\begin{array}{l}\text { Lung tissue } \\
\text { +ve for } \\
\text { Mp/No of } \\
\text { samples }\end{array}$ & $\begin{array}{l}\text { Total } \\
\text { +ve/600 } \\
\text { samples }\end{array}$ & $\begin{array}{l}\text { Percentage } \\
(\%)\end{array}$ \\
\hline Chitral & $5 / 29$ & $2 / 21$ & $9 / 32$ & $13 / 34$ & 29 & 25 \\
\hline Swat & $7 / 24$ & $1 / 19$ & $5 / 30$ & $6 / 25$ & 19 & 19.38 \\
\hline $\begin{array}{l}\text { Gilgit } \\
\text { Baltistan }\end{array}$ & $9 / 26$ & $2 / 24$ & $13 / 27$ & $16 / 26$ & 40 & 38.83 \\
\hline Total & $21 / 79$ & $5 / 64$ & $27 / 89$ & $35 / 85$ & 317 & 27.7 \\
\hline
\end{tabular}

\section{Figures}
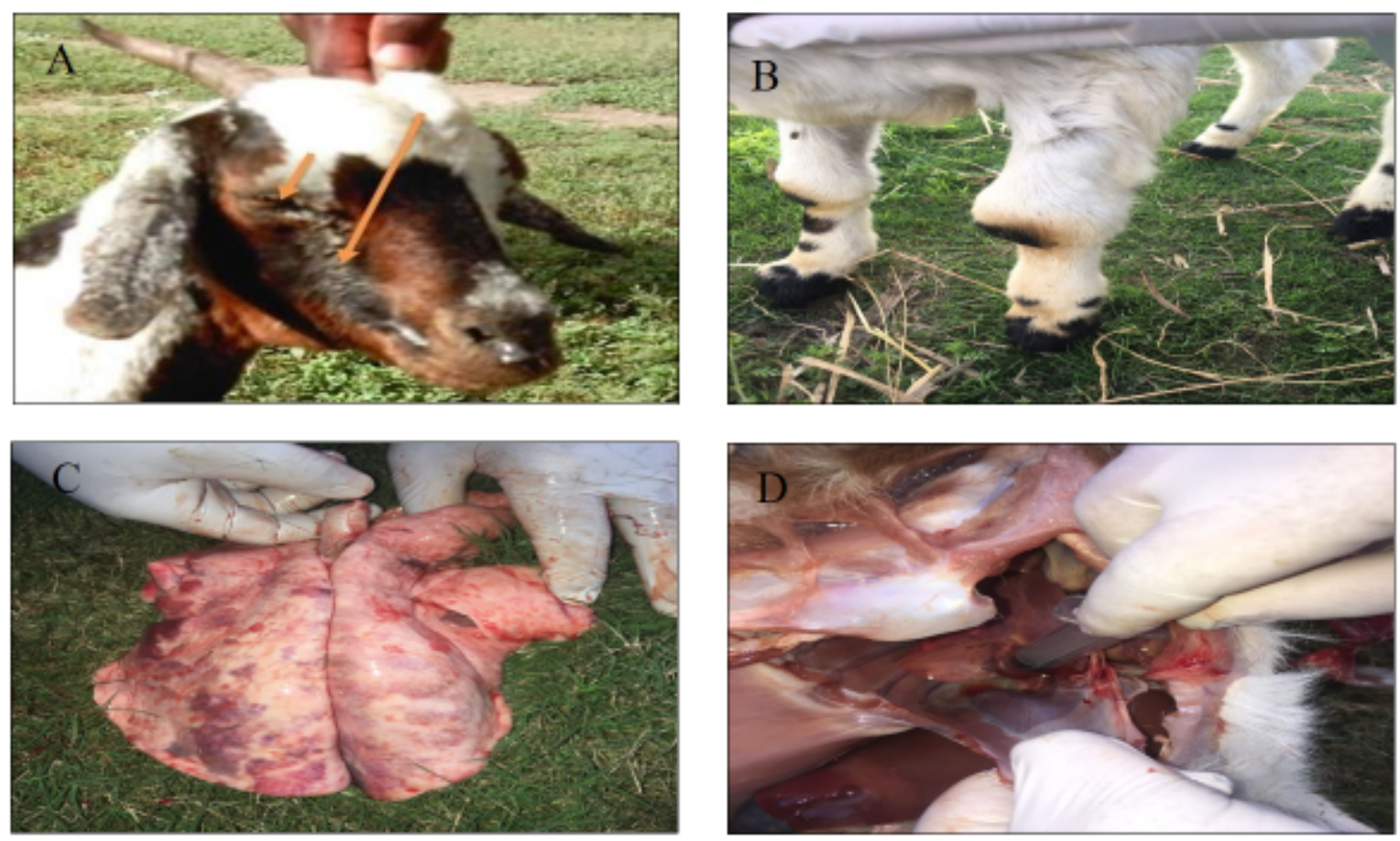

Figure 1

(A) Shows conjunctivitis and mucopurulent nasal discharge, (B) shows swelling of joints in kid, (C) postmortem examination shows unilateral hepatization (D) shows pleural fluid aspirated through sterile syringe. 


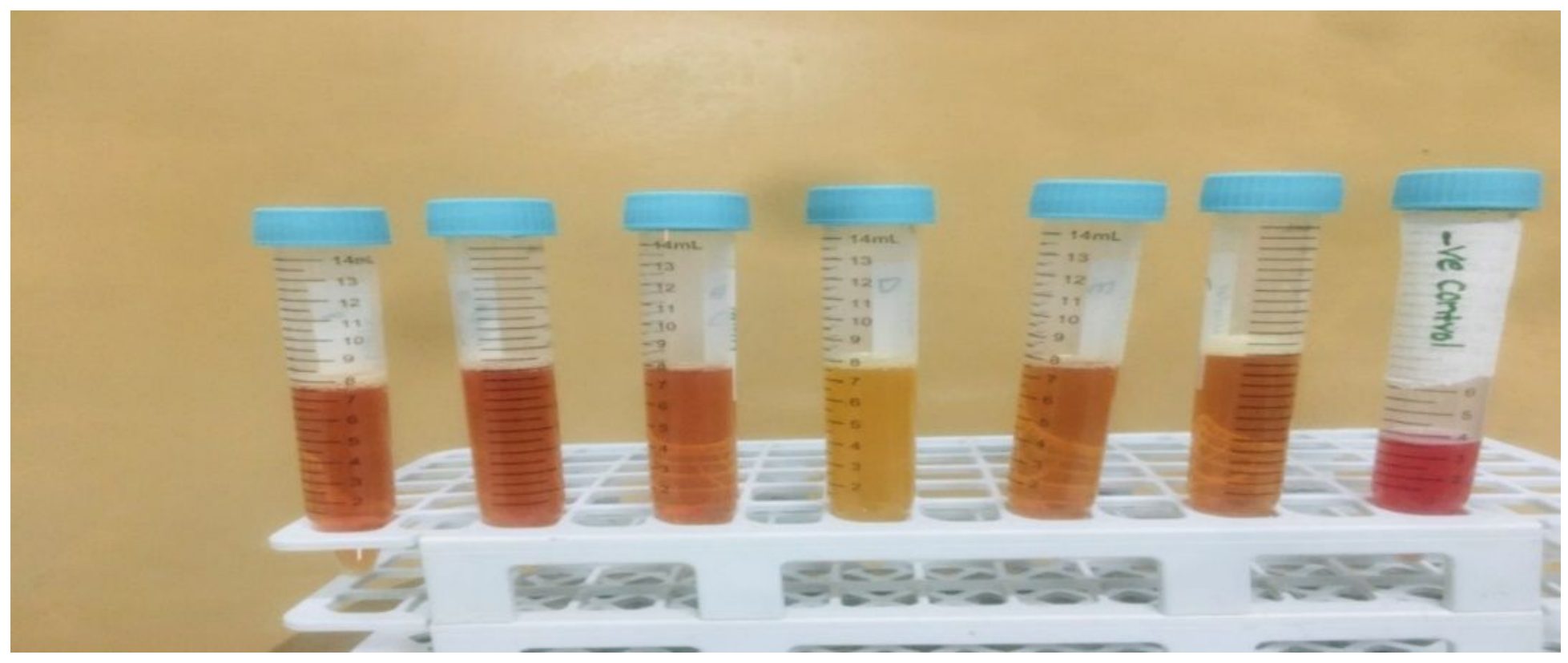

Figure 2

Cultivation of field samples collected from naturally infected goats in PPLO broth: from left to right first 6 samples shows Mycoplasma putrifaciens growth on 2nd day post incubation while last tube placed as a negative control.

\section{Figure 3}


Mycoplasma putrifaciens (Mp) validation by PCR: DNA Marker (M). Lane 1 indcates Negative control. Lane 2 and 3 indicates field samples revealed Mp local isolates by generating an amplicon of 540bp. Lane 4 indicates as a positive control.

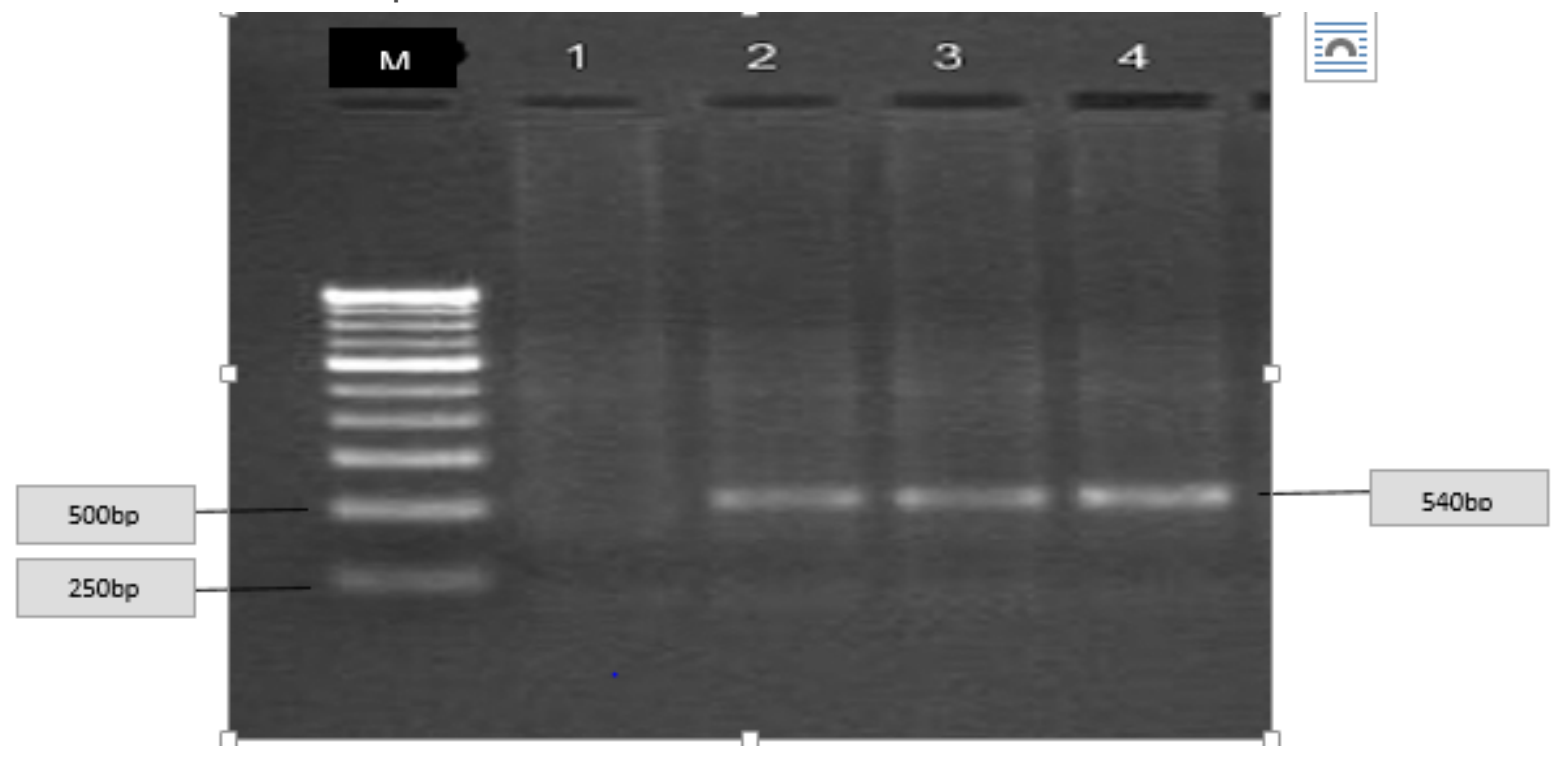

\section{Figure 4}

Purified colonies of Mycoplasma putrifaciens having a very small center on PPLO agar post 2-3 days incubation. 